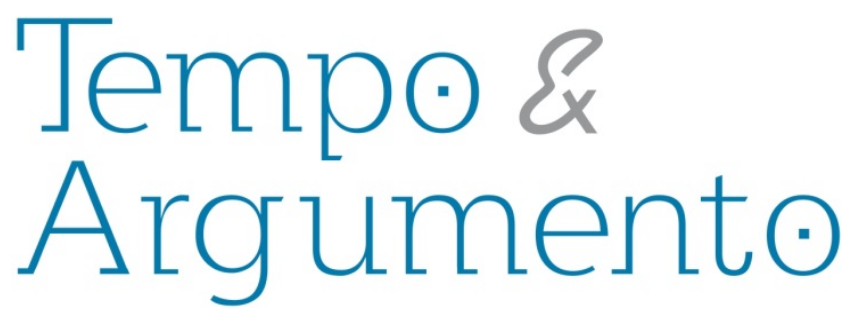

\title{
Bob Cuspe: resistências microscópicas, contracondutas e a potência do "não" nos quadrinhos underground de Angeli
}

\begin{abstract}
Resumo
O artigo analisa o personagem Bob Cuspe, criado pelo cartunista Angeli, à luz do conceito de "contracondutas", ou seja, como formas inovadoras de resistência política que se fundam na desmobilização das redes de poder e de seus representantes. A partir do exame do personagem especificamente as características demarcadas na história inaugural -, e das referências discursivas aplicadas para lhe dar sentido, intenta-se assinalar como o seu modo de vida expressa novas formas de resistência contemporâneas, na medida em que constitui um novo mundo, com regras próprias de convívio e de estar junto e, ao mesmo tempo, mantém presente uma condição crítica. Com essa análise, pretende-se refutar o argumento, frequente em estudos existentes sobre o mesmo, de que o personagem manifesta uma condição alienada do contexto social e político no qual está inserido. Finalmente, defende-se a premissa de que a revista Chiclete com Banana, onde foram veiculadas as histórias de Bob Cuspe, foi um espaço criado para reverberar um humor assumidamente melancólico e niilista, que não se identifica com as intenções e/ou utopias revolucionárias da geração anterior de artistas, políticos e intelectuais, e que se torna representativa de grande parte da juventude brasileira que se formou silenciada e sob o impacto do medo promovido pelo terror do estado ditatorial.
\end{abstract}

Palavras-chave: Histórias em Quadrinhos. Angeli, 1956.

Humor Gráfico.

\author{
Maria da Conceição Francisca Pires \\ Doutora em História pela Universidade \\ Federal Fluminense. Professora do \\ Departamento e do Programa de Pós- \\ Graduação em Historia da Universidade \\ Federal do Estado do Rio de Janeiro - UNIRIO \\ Brasil \\ conceicao.pires@uol.com.br
}

\author{
Para citar este artigo: \\ PIRES, Maria da Conceição Francisca. Bob Cuspe: resistências microscópicas, contracondutas e a \\ potência do "não" nos quadrinhos underground de Angeli. Revista Tempo e Argumento, \\ Florianópolis, v. 9, n. 20, p. 75 - 98. jan./abr. 2017.
}

DOI: $10.5965 / 2175180309202017075$

http://dx.doi.org/10.5965/2175180309202017075 


\title{
Bob Cuspe: Microscopic Resistances, Contraconducts and the Power of "Not" in the Underground Comics by Angeli
}

\begin{abstract}
The article examines the character Bob Cuspe, created by the cartoonist Angeli, in the light of the concept of "contracondutas", that is, as innovative forms of political resistance that are based on the demobilization of the networks of power and their representatives. From the examination of the character - specifically the characteristics demarcated in the inaugural story -, and the discursive references applied to give it meaning, it is tried to point out how his way of life expresses new forms of contemporary resistance, considering as it constitutes a new world, with its own rules of conviviality and being together and, at the same time, keeps a critical condition in mind. This analysis intends to refute the argument, frequent in existing studies about the same, that the character manifests a condition alienated from the social and political context in which it is inserted. Finally, it is defended the premise that the magazine Chiclete com Banana, where the stories of Bob Cuspe were published, was a space created to reverberate an assumedly melancholic and nihilistic mood, that does not identify with the intentions and / or revolutionary utopias of the generation of artists, politicians and intellectuals, and that it becomes representative of a great part of the Brazilian youth that was formed silenced and under the impact of the fear promoted by the terror of the dictatorial state.
\end{abstract}

Keywords: Comics. Angeli, 1956. Humour Graphic.

No verão de 1989, a revista americana National Interest publicou o ensaio do funcionário do departamento de Estado norte-americano, Francis Fukuyama, no qual foram pincelados os primeiros sinais da premissa de que o triunfo da democracia liberal capitalista representava a etapa final da evolução ideológica humana; posteriormente, em 1992, essa ideia foi ampliada no seu livro "O Fim da História e o Último Homem”. Alguns meses depois, o mundo assistiu, não sem espanto, a queda do muro de Berlim, evento que se tornou, por motivos óbvios, uma das melhores representações da crise de 
Para alguns, a queda do muro foi a materialização do fim da história anunciado por Fukuyama. Para outros, era o limiar de uma nova ordem mundial que tornava urgente o esboço de novas diretrizes teóricas capazes de responder as indagações pendentes no recente contexto geopolítico e demarcar novas formas de fazer política. Quase vinte anos depois, seguindo no intento de apresentar uma resposta para as questões que permaneciam acesas diante do novo cenário internacional, Samuel P. Huntington (1997) apresenta o diagnóstico de que a nova forma de organização mundial se fundamentaria basicamente em fatores culturais, e não mais exclusivamente por motivações ideológicas, econômicas ou políticas.

Não faz parte dos meus objetivos, aqui neste artigo, aprofundar as teses desses dois pensadores, mas gostaria de assinalar que, em comum, Fukuyama e Huntington apresentam a compreensão de que uma nova ordem pós-ideológica debutou ao final do século XX, o que implica, por sua vez, o entendimento da falência de discursos ou ideais revolucionários, uma vez que a inexorabilidade dessa nova ordem tornaria obsoleta toda tentativa de se contrapor ao que se apresentava como estabelecido.

Embora esse debate teórico não pareça estar diretamente associado ao objeto que será abordado nesse artigo - o personagem Bob Cuspe e a revista Chiclete com Banana -, ele nos serve como parâmetro da discussão que se desenvolvia no interior do ambiente intelectual à época de seu surgimento, os anos 80 , dando forma a um conjunto de pensamento que pôs em xeque as chamadas "grandes explicações" da história e a compreensão da urgência de construção de novas teorias que se mostrassem atentas as novas condições contemporâneas e que dessem sustentação às formas pontuais de manifestação e de oposição (FOUCAULT, 2008; DELEUZE, 2010).

Uma vez que compreendo que os ecos desse debate sobre a crise das grandes ideologias reverberaram de maneira bastante contundente também no campo artístico, optei por pensar nosso objeto como parte dessa atmosfera de crise que se desenvolve no campo do conhecimento. Na América Latina, esse aspecto se torna mais contundente na medida em que as artes, ainda nos anos 70, se somaram à produção intelectual para fazer frente às ditaduras militares instauradas, fortalecendo e ampliando, para outros espaços, os exercícios de oposição. 
Assim, a crítica aos grandes modelos interpretativos da história e o debate sobre o “fim" das grandes correntes ideológicas somados ao contexto de abertura política que se desenvolve no final da década de 70, ressoou também entre os cartunistas, demarcando uma nova postura da produção humorística; a partir dos anos 1980, coloca-se em suspensão a quase obrigatoriedade de se pensar e atuar politicamente de forma tão incisiva.

Nas décadas de 60 e 70 o intenso debate político-ideológico, centrado em referenciais teóricos importantes e bem delimitados, se desenvolveu, dentre outros veículos, através da imprensa alternativa e teve no chamado "humor de guerrilha" uma fonte importante e fundamental para a expansão da crítica e da resistência à ditadura militar. Nesse tipo de produção, que tinha como características centrais o engajamento e o conteúdo crítico, se destacaram o jornal Pasquim e o trabalho do cartunista Henfil, publicado tanto no Pasquim como no Jornal do Brasil e, ainda, na revista de sua autoria, Fradim, que circulou entre os anos de 1973 e 1980.

A sátira política - veiculada através de quadrinhos, charges e caricaturas - teve uma participação mais do que especial na propagação de uma crônica da violência cotidiana exercida pelo Estado contra seus opositores. Angeli fez parte dessa geração de cartunistas - como Henfil, Jaguar, Millôr, dentre outros -, que nos anos 70 empregou o humor com uma função política, colocando em discussão tanto as condições de vida durante a ditadura, como as pressões vividas no âmbito profissional. Nessa perspectiva, o humor funcionaria como uma forma de colocar à mostra as arbitrariedades do regime ditatorial instaurado e como um instrumento de ação política.

Gradativamente, com as mudanças no contexto político e social e o desenvolvimento de outras estratégias de ação e atuação políticas, a sátira política passa a dividir espaço significativo com a crítica de costumes, que assume como objetivo abordar especialmente as práticas da emergente classe média nos grandes centros urbanos. Pode-se afirmar que Angeli está à frente dessa mudança que envolve o tipo, o estilo, a temática e os sentidos do humor que se passou a construir e que, sem dúvida, está associada às transformações que a sociedade brasileira vinha experimentando, sobretudo no que tange à forma de fazer política. 
É nesse processo de transição que surge a revista Chiclete com Banana, criada por Arnaldo Angeli Filho ${ }^{1}$, em parceria com Toninho Mendes em outubro de 1985, e que expressa em seu conteúdo uma nova forma de conceber a "função" do humor, repensando tanto a concepção de crítica política, como a importância dessa crítica para o contexto contemporâneo. Bastante ilustrativo dessa reflexão é o depoimento de Angeli, dado em uma entrevista concedida à revista Playboy:

Uma vez, eu estava procurando uma cara do Delfim Netto para ilustrar uma coluna de humor e achei uma foto dele com uma charge do Chico Caruso emoldurada. Por que um cara emoldura uma charge que lhe é crítica? Ou foi porque a charge não funcionou ou ele é mais inteligente do que o cartunista e resolveu reverter a situação em seu favor. É o preso emoldurando a própria sentença. Quando olhei aquilo, comecei a analisar minhas charges e pensei: porra, estão parecendo bonequinhos engraçadinhos. Não dava pra desenvolver uma opinião numa situação de ditadura. Porque a minha tentativa é derrubar o governo. É logico que o cara não vai cair com a minha charge, mas gosto de pensar que vou conseguir. (PLAYBOY, 2006, p. 68)

$\mathrm{Na}$ esteira do movimento de contracultura e inspirado nos quadrinhos underground $^{2}$ que já tinham um espaço consolidado nos Estados Unidos e começavam a dar os primeiros passos no Brasil durante os anos $70^{3}$, a revista Chiclete com Banana prioriza em seu interior os quadrinhos de costumes e questões próprias da cultura de uma juventude que não mais se interessava em se apresentar compromissada com

\footnotetext{
${ }^{1}$ A produção quadrinística do paulista Angeli ganhou destaque no Brasil após a conquista do segundo lugar no Salão do Humor de Piracicaba, em São Paulo, no ano de 1972. Antes disso, atuava na produção do humor gráfico dos panfletos e jornais sindicais que circulavam no final dos anos 1960 e começo dos anos 1970 no Brasil. A partir da conquista do prêmio no Salão de Humor, passou a colaborar no jornal Folha de São Paulo, onde se tornou responsável pelo cartum editorial e passou a publicar diariamente no caderno Ilustrada a tira Chiclete com Banana. Durante os anos 70, colaborou ainda com a produção de charges políticas para os jornais alternativos Pasquim, Versus, Movimento. Participou da criação da Circo Editorial, em que publicou o primeiro álbum com história de Bob Cuspe, e da revista Chiclete com Banana na qual reuniu as tiras produzidas na Folha até então e os seus diferentes personagens. Até maio de 2016, contribuiu nos quadrinhos diários da Folha. Atualmente, colabora esporadicamente na página A2 e na seção Quadrão, ambas na Folha de São Paulo.

2 "o underground teve seu ápice na figura do norte-americano Robert Crumb. Fortemente influenciado pela geração Beat e movimento flower power, ele foi o criador de personagens transgressoras e amorais e de mulheres grosseiramente esculturais e libertinas, como a negra Angelfood Macspade e a Devil Girl". (DANTAS, 2004, p. 21)

3 Publicações anteriores já haviam adotado o estilo underground, como a revista Balão, que se tornou um marco inaugural da produção marginal, e Bicho que, por sua vez, se sobressaiu por expandir o número de publicações, alcançando de 12.000 a 15.000 cópias, ocupando espaço também nas bancas de jornais. Ver CIRNE, 1975.
} 
Essa nova tendência dos quadrinhos e o comportamento supostamente “apolítico" de cartunistas como Laerte, Angeli, Paulo Caruso, Luis Gê, Glauco, dentre outros, ganhou maior reverberação com uma matéria publicada em 1985, pela revista Istoé, colocando em pauta os quadrinhos de costumes, estimulando uma acirrada polêmica entre os "antigos" e os "novos" cartunistas, representados por Henfil e Angeli, respectivamente.

Desse conflito entre os cartunistas, interessa-me pincelar a seguinte declaração de Angeli:

(...) se meu trabalho serve ou não à direita, isso na minha cabeça está resolvido. Serve a direita o cacete! Muito menos a esquerda. Serve sim, para tirar sarro desse insetozinho mal resolvido chamado homem. Seja ele de situação ou de oposição. Ridículo não tem ideologia e quando tentar ter fica muito mais ridículo. Humorista não presta para posar de deputado e muito menos derruba governos. Quando muito, ilustra folhetins revolucionários, o que deixa de ser humor pra virar propaganda. Meu trabalho não tenta só se alimentar da fome do Nordeste, mas também de outras fomes que roncam na cabeça do ser humano. Se não podemos falar de nossas fraquezas corremos o risco de virarmos uns asnos cagadores de regras políticas e não foi bem pra isso que vim ao mundo. (ANGELI, 1985, p. 41)

Essa assertiva deixa claro que o propósito de sua produção é trazer à tona um humor que prioriza as questões comportamentais, em detrimento daquelas consideradas especificamente políticas, mas que nem por isso deve ser caracterizada simplesmente como "apolítica", e essa é a premissa que pretendo desenvolver nesse artigo. Entendo que, assim como no campo da produção do conhecimento houve uma tentativa de construir novas formas de pensar as novas condições geopolíticas, econômicas e culturais - tal qual enunciado a partir das proposições de Fukuyama e Huntington -, esse tipo de produto cultural representa uma forma alternativa de exposição e crítica aos sistemas de ordenamento políticos e sociais estabelecidos.

Um aspecto relevante da produção de Angeli é a capacidade que apresenta de imergir nas questões próprias de sua época, conseguindo tornar visível as contradições e a condição de crise que permeava a sociedade brasileira do período. É dessa forma que seus personagens podem ser concebidos como contemporâneos, no sentido proposto 
por Agamben (2009). O caráter de contemporâneo que atribuo à revista Chiclete com Banana e, mais especificamente, aos personagens de Angeli, refere-se à relação que desenvolve com o seu tempo. Personagens como Bob Cuspe ou Rê Bordosa, por exemplo, se apresentam mergulhados no seu tempo, no entanto, dele se distanciam e é através desse distanciamento que se tornam capazes de dar a ver as contradições e problemas daquele mesmo tempo. São contemporâneos porque possuem a habilidade de "neutralizar as luzes que provêm da época para descobrir as suas trevas, o seu escuro especial, que não é, no entanto, separável daquelas luzes" (AGAMBEN, 2009, p. 63).

Assim, dentro dessa linha de raciocínio, concebo a revista Chiclete com Banana como um espaço criado para reverberar um humor assumidamente melancólico e niilista, que não se identifica com as intenções e/ou utopias revolucionárias da geração anterior de artistas, políticos e intelectuais, e que se torna representativa de grande parte da juventude brasileira que se formou silenciada e sob o impacto do medo promovido pelo terror do estado ditatorial.

Para desenvolver minha premissa, irei apresentar de forma resumida a revista Chiclete com Banana para, em seguida, me dedicar à análise do universo discursivo e comportamental do personagem Bob Cuspe, cujas histórias o tornaram uma das melhores representações dos undergrounds comix. Junto com a personagem Rê Bordosa, Bob Cuspe tornou-se fundamental para dar visualidade aos códigos comportamentais e às linguagens específicas dos circuitos alternativos característicos dos anos 80.

O procedimento analítico empregado tem como base o exame das referências discursivas aplicadas para dar sentido ao personagem - especificamente as características demarcadas na história inaugural. Embora considere que a soma dos expedientes gráficos - enquadramento, formato, ângulo de visão, letras e outros elementos que figurem como metáforas visuais - é parte importante da estratégia empregada pelo autor para levar ao leitor a carga de expressividade almejada naquela narrativa, estes não serão o foco de minha análise.

Para consubstanciar minha proposta, me dedicarei ao exame da história inaugural do personagem, identificando como o seu modo de vida expressa novas formas de resistência contemporâneas, na medida em que, por um lado, constitui um novo mundo com regras próprias de convívio e de estar junto e, por outro, mantém presente uma 


\section{Chiclete com Banana e o mercado de quadrinhos para adultos no Brasil}

A revista Chiclete com Banana foi lançada em 15 de outubro de 1985, pela Circo Editorial, editora dirigida pelo jornalista, poeta e editor de arte Antônio de Souza Mendes Neto, que ficou conhecido como Toninho Mendes, amigo de infância de Angeli. O investimento no trabalho de Angeli fez parte dos interesses de Toninho Mendes para entrar no mercado de revista em quadrinhos voltado especificamente para um público adulto (VERGUEIRO, 2014).

Tratou-se de um empreendimento ousado, pois significou investir em um mercado ainda destinado ao público infantil e com a presença maciça dos quadrinhos norteamericanos. A parceria com Angeli mostrou-se uma excelente opção, uma vez que este último já encontrava respaldo da crítica e do público para o seu trabalho publicado diariamente na Folha de São Paulo, desde que ganhara o prêmio no $2^{\circ}$ Salão de Humor de Piracicaba, em 1975.

Antes da edição da revista propriamente dita, a Circo Editorial lançou a Série Traço e Riso, com o álbum Chiclete com Banana, que reunia tiras de Angeli publicadas na Folha de São Paulo. Em entrevista concedida para Silva (2002), Angeli afirmou que o sucesso da publicação - que alcançou 11 edições - foi fundamental para o lançamento posterior da revista.

A primeira edição da Chiclete com Banana saiu com capa colorida, quarenta e oito páginas em preto e branco e uma tiragem de 20 mil exemplares. No terceiro número, a tiragem aumentou para 40 mil exemplares, alcançando a surpreendente faixa dos 110 mil exemplares nos números 7 e 8 e, posteriormente, manteve a margem dos 90 mil exemplares, algo ainda não alcançado por revistas do mesmo gênero (SILVA, 2011). Por cinco anos, manteve a periodicidade bimestral, perfazendo um total de vinte e quatro edições e alguns números especiais (VERGUEIRO, 2014).

Dado o sucesso alcançado, Angeli passou a se dedicar quase que integralmente à revista. Para isso, se desvinculou da criação de charges para a Folha de São Paulo, para se tornar responsável pela produção da revista. Assim, até o número 11, vamos identificar 
uma quase que total exclusividade dos personagens de Angeli; a partir do número 12 alguns colaboradores, como Laerte, Luiz Gê, Paulo Caruso, Furio Lonza, Luiz Gustavo e Glauco, antes eventuais se tornam frequentes, eximindo Angeli da total responsabilidade pela revista.

Inicialmente, o carro-chefe da revista eram os personagens Rê Bordosa e Bob Cuspe, já conhecidos do público através da Folha de São Paulo. Posteriormente, com a entrada de novos colaboradores, outros personagens e seções ganham espaço e se destacam. Tudo indica que essa inserção de novos colaboradores, somada aos rumos que a relação entre autor, personagem e leitores estava tomando, foram fundamentais para que Angeli tomasse a decisão que mais impressionou seus leitores: matar Rê Bordosa.

A edição A morte de Rê Bordosa saiu em dezembro de 1987 e foi a mais vendida, duas edições com mais de 200 mil exemplares (VERGUEIRO, 2014). Aliás, esta não foi a única personagem morta pelo autor, Bob Cuspe e Meiaoito também foram assassinados pelo autor.

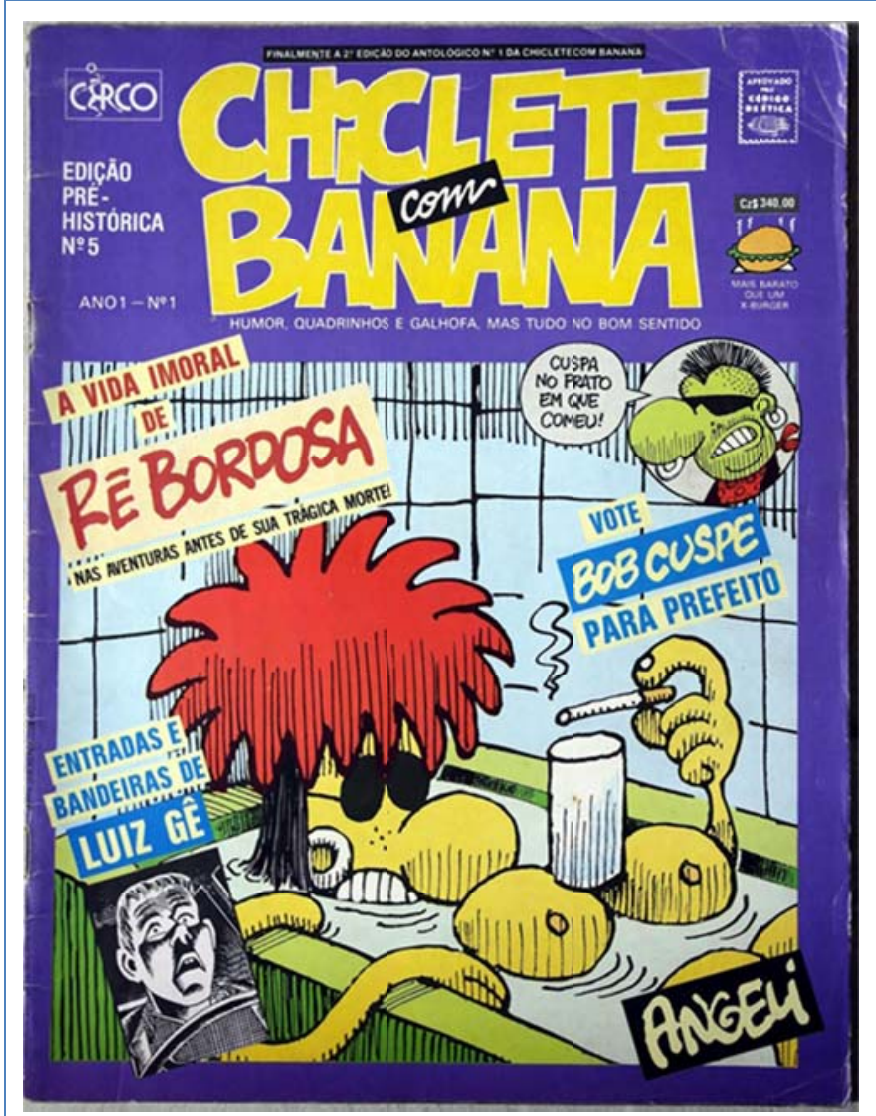

FIG. 01. Capa da revista Chiclete com Banana n. 1. Circo Editorial. Outubro de 1985. Arquivo pessoal.
Na capa da primeira edição figuram os personagens conhecidos do público cativo da Folha de São Paulo: Rê Bordosa e Bob Cuspe. Posteriormente, novos personagens de Angeli foram integrados à revista compondo a fauna exótica que, através do hiperbolismo, do rebaixamento e da quebra das convenções verbais (utilização de palavrões e de gestos obscenos), suspendiam práticasi e valores sociais considerados padrões e criavam situações propícias para fazer alusões às questões relacionadas à sexualidade (masculina e feminina), homossexualidade, drogas, cotidiano urbano, etc. 
O editorial de lançamento da revista anunciou não só a ruptura com o modelo engajado de produção artística, mas também expressou sua postura acerca do mercado editorial voltado para os quadrinhos norte-americanos, até então hegemônicos no Brasil. Neste, fica evidente também um certo ceticismo com as possibilidades criadas pelo passado recente, ao mesmo tempo em que prestigia a indiferença e afirma a intenção em promover, através dessa "lógica atormentada", o potencial crítico do leitor (NOVAES, 1996).

Como forma de apresentação mais geral da revista, dissertarei sobre alguns aspectos que se destacam na edição inaugural the conferindo um perfil e, ao mesmo tempo, uma certa singularidade. O primeiro ponto que chama a atenção é o fato de que, ao contrário de grande parte da

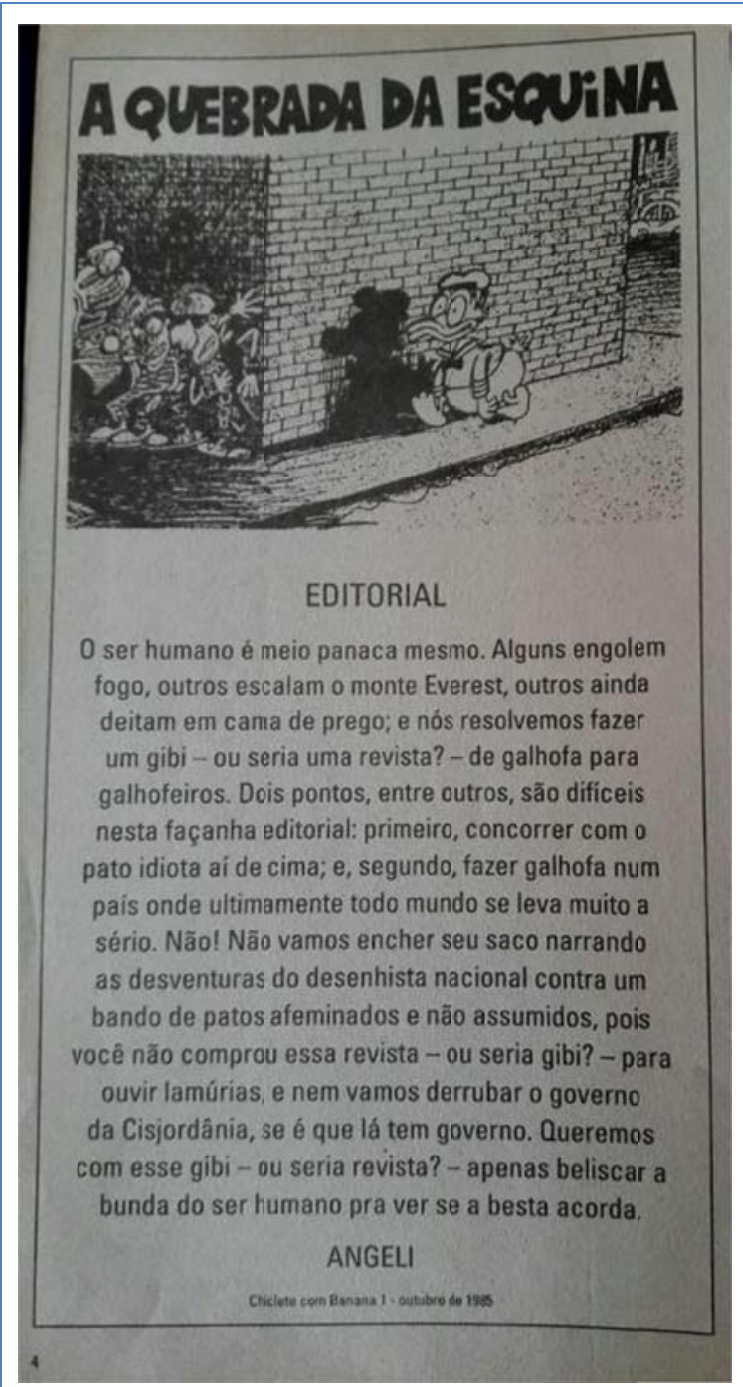

FIG. 02. Fonte: Chiclete com Banana n. 1. Circo Editorial. Outubro de 1985, p. 3. Arquivo pessioal. mídia impressa do período, o autor apresenta a opção de participar de forma diferenciada do debate político da época. Sem se integrar a vínculos políticos partidários, Angeli utiliza essa edição para propor o que podemos definir como a "anticandidatura”' de Bob Cuspe. “Anticandidatura” porque não se identifica um caráter propositivo, já que nas palavras do autor “Bob Cuspe é o caos. Bob Cuspe é o fim”.

Assim, essa anticandidatura pode ser pensada como um mecanismo empregado para se contrapor ao clima político do período, com o processo de redemocratização em curso promovendo intensas transformações no cenário político brasileiro. A opção, anunciada no editorial, é de manter-se desvinculado de tendências político-partidárias, apostando "no alvo e não nos atiradores", ou seja, contrária ao status político 
Um segundo aspecto que destaco é a intenção aberta de expor uma visão autoral sobre a realidade vivida, sem que isso representasse um testemunho da história. Esse aspecto se torna evidente quando o autor se representa na história inaugural como uma espécie de cabo eleitoral de Bob Cuspe, uma espécie irônica de guia que iria apresentá-lo ao leitor.

Através de seus personagens, e especificamente da anticandidatura de um personagem que carrega "um longo e incontestável currículo de transgressor", Angeli desenvolveu uma crítica determinantemente estrutural e não só conjuntural, ao mesmo tempo em que explicita suas representações sobre um conjunto de conceitos e ideias vigentes.

Um terceiro ponto a ser assinalado refere-se às características dos personagens que, comumente, são percebidos como estereótipos de diferentes agrupamentos sociais. Alguns estudos, por exemplo, associam Bob Cuspe ao movimento anarquista ${ }^{4}$; para outros, ele representa os punks ${ }^{5}$; há ainda quem o identifique como a negação do modelo de homem urbano e dos valores e padrões considerados normais ${ }^{6}$. Compreendo que personagens como Bob Cuspe e Rê Bordosa transcendem a condição de simples estereótipos, entendendo por estereótipo “o que designa convicções preconcebidas acerca de classes e indivíduos, grupos e objetos resultantes não de uma estimativa espontânea de cada fenômeno, mas de hábitos de julgamentos e expectativa tornando rotina" (SILVA, 1986, p. 341).

Ao prescindir do juízo de valor, esses personagens não se tornam mera estereotipia do urbano. Eles carregam em si referências do autor e da coletividade a qual está tentando retratar, e suas ações e falas remetem o leitor a formas de ser e pensar da coletividade no qual esse tipo estaria associado, dando a ver a expressiva mudança que se processa nas práticas, discursos e sensibilidades do seu tempo. Podem ser pensados, portanto, como alegoria de um espírito de época.

\footnotetext{
${ }^{4}$ SANTOS, 2012.

${ }^{5}$ SILVA, 2002.

${ }^{6}$ LIMA, 2013.
} 
Nas palavras de Diniz:

Os seus personagens representam partículas de um contexto maior, que podem ser reconhecidas nestes fragmentos do contexto social. Mesmo sendo fruto da exteriorização de um artista, esta partícula ou particularidade compõe uma construção dialética, um conjunto de elementos integrados e dinamizados. Mas, em momento algum determinam uma classe em si, senão nos personagens que representam uma classe como Psico, o Burguês, que é um caso à parte, por ser uma crítica contra a postura dos valores e da visão burguesa sobre o mundo (DINIZ, 2001, p. 59)

Os personagens materializam a pretensão do autor de se manter afastado das tradições políticas e culturais que ganharam espaço no Brasil a partir dos anos 70 e que procuravam se apresentar como uma opção alternativa democrática ao autoritarismo vigente naqueles anos.

Rê Bordosa e Bob Cuspe, que estampam a capa da revista, são o oposto dessa pretensão revolucionária e otimista que animou os movimentos sociais e políticos nos anos 60/70, e expressam uma visão apocalíptica da realidade vivida e da política. Ao mesmo tempo, por não se apresentarem como estereótipos de tribos urbanas, podem ser concebidos como signo de uma época. Assim, embora não sejam o "espelho do social. (...) não refletem o social, nem se refletem no social - é o espelho do social que nelas se despedaça" (BAUDRILLARD, 2004, p. 56).

Finalmente, destaca-se a relação estabelecida com os meios e modos de produção, distribuição, comercialização e divulgação da revista. Embora o editorial do primeiro número faça uma crítica ácida aos quadrinhos norte-americanos hegemônicos no Brasil, nos demais números não vamos identificar essa preocupação em desenvolver a crítica às instituições culturais ou à imprensa institucional burguesa e sua ideologia.

A Chiclete com Banana se reconhecia como parte da indústria cultural, mas não expressava um entusiasmo por essa condição. Como produto cultural com influências abertamente underground, a revista inovou por colocar em primeiro plano aquilo que era considerado intolerável, repulsivo ou escandaloso e ao valorizar os novos modos de fruição e consumo, que naquele momento passam a ser individuais, e que incidem na construção de práticas identitárias entre leitores e personagens. 
Nesse sentido, o que muda é a sua posição dentro da cultura contemporânea, deixando de ser uma força clandestina se torna protótipo de uma época e se propaga através de um consumo e comercialização amplos e vorazes (JAMESON, 1985).

Conforme Vergueiro, o diferencial da Chiclete com Banana estava não só na temática adotada, mas também em sua:

Apresentação, sua estruturação interna. Suas histórias se baseiam predominantemente no formato da tira, (...) uma característica que tem implicações para a narrativa da revista e consequentemente para sua análise. (VERGUEIRO, 2014, p. 41)

A revista foi finalizada em agosto de 1995, após a publicação do álbum $F H C$, Biografia não autorizada, que reunia charges feita por Angeli durante o governo de Fernando Henrique Cardoso. Vários foram os motivos apontados para esse desfecho: oscilações da economia, má gestão administrativa, excesso de trabalho. Creio que as palavras de Laerte resumem as motivações para esse desfecho:

Foi uma combinação de crise econômica do país com uma falta de fôlego financeiro da editora, como comprar papel, fazer estoque, e tátátá com uma estafa dos autores, mesmo porque cada revista daquelas era feita por uma pessoa, basicamente. A Chiclete com Bananaera feita por Angeli, a Piratas era feita por mim. A Geraldão não era feita pelo Glauco, ela era feita pelo Toninho. O estafado no caso do Geraldão era o Toninho. Mas, enfim, era uma coisa assim meio "one man show", então o sujeito aguenta durante um tempo só, depois... (LAERTE apud SANTOS, 2012, p. 111)

\section{Bob Cuspe: contracondutas e a potência do "não"}

Para a análise do personagem Bob Cuspe, buscarei ancoragem na noção de contracondutas que figuram, de forma esparsa, em algumas reflexões de Michel Foucault (2008; 2004) para abordar alguns tipos de revoltas que não são especificamente econômicas ou políticas, embora estejam associadas a outras formas de conflitos (GRABOIS, 2011).

No curso Segurança, Território, População (2008) Foucault aborda as relações entre pastorado e governo, vislumbrando pontos de resistência que se desenvolvem no próprio campo do pastorado e que teriam como objetivo "querer ser conduzido de outro 
modo, por outros condutores e por outros pastores, para outros objetivos e para outras formas de salvação, por meio de outros procedimentos e de outros métodos" (apud GRABOIS, 2011, p. 15).

Contracondutas compreendem, pois, "formas de resistência ao poder como conduta" e que buscam "escapar da conduta dos outros (...) definir para cada um a maneira de se conduzir" (FOUCAULT, 2008, p. 257). Essa noção parece pertinente para abordar a primeira aparição de Bob Cuspe, que foi anunciada pelo autor como uma possibilidade política contrária à multidão de personagens - com suas respectivas ideologias - que aparecem no quadro: Pinochet, hare krishnas, o Papa, Ronald Reagan em postura de disputa abraçado ao globo, judeus, dentre outras figuras da época.

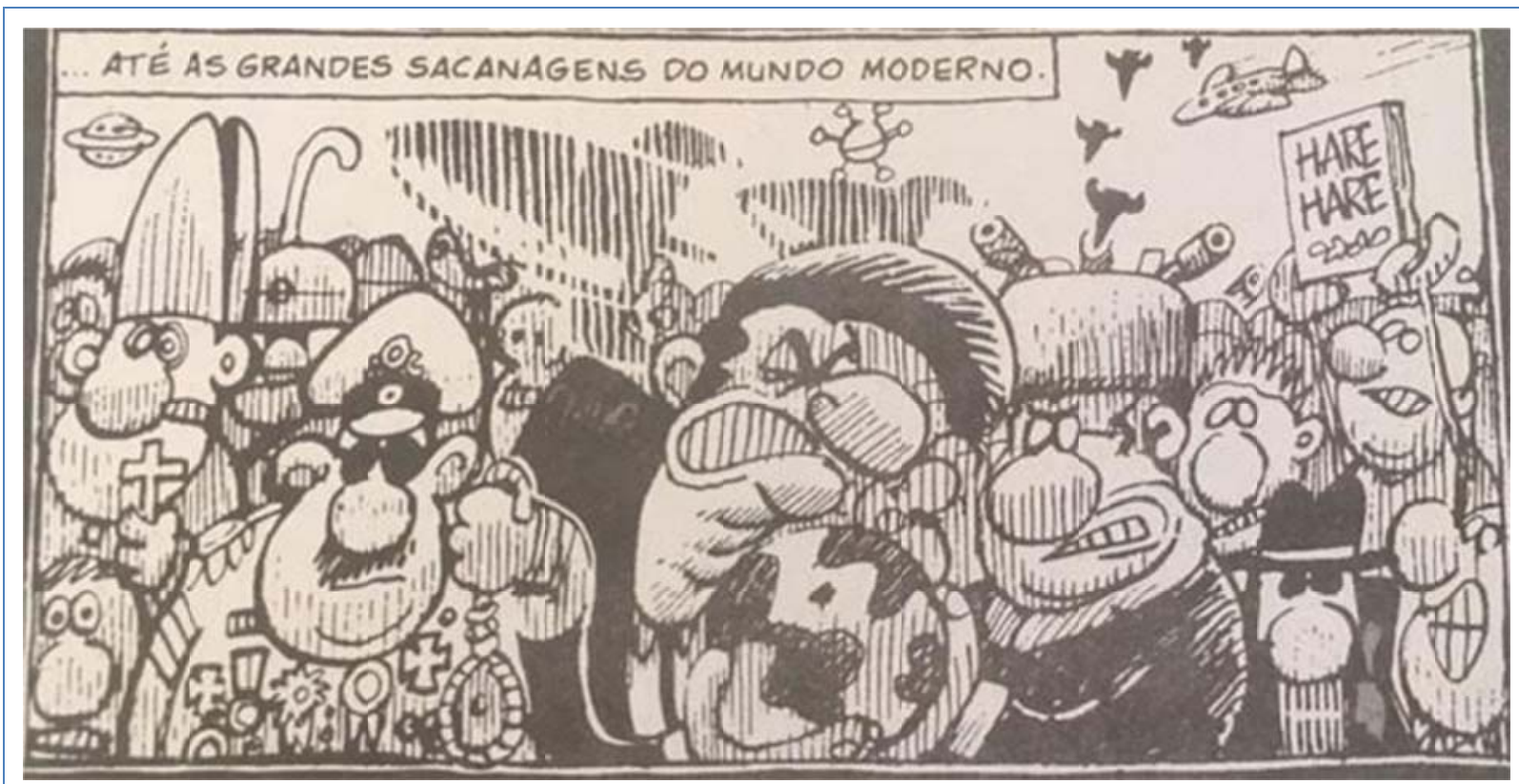

FIG. 03. Fonte: Chiclete com Banana n. 1. Circo Editorial. Outubro de 1985, p. 3. Arquivo pessoal.

Com essa aparição, o personagem e suas ações adquirem um outro sentido, que na minha compreensão não é simplesmente a expressão de uma conduta indiferente ou apolítica. A meu ver, sua recusa manifesta através das escandalosas cuspidas não expressa uma indiferença ou desistência absoluta, ou ainda, um vazio comportamental.

Proponho pensá-las - não só as cuspidas, como sua anticandidatura e o seu comportamento em geral - como contracondutas, ou seja, reações fragmentárias às condutas sociais propostas. Especificamente entendo que suas ações representam formas de resistências microscópicas “improváveis, espontâneas, violentas, 
irreconciliáveis", que se expressam de maneira distinta dos padrões usuais de luta política, funcionando "fora das lógicas das grandes rupturas radicais (...), elas são, antes, pequenos pontos de inversão (...), de desobediência (...) e de colocação das próprias formas de dominação em julgamento (...)" (ALVIM, 2011, p. 12).

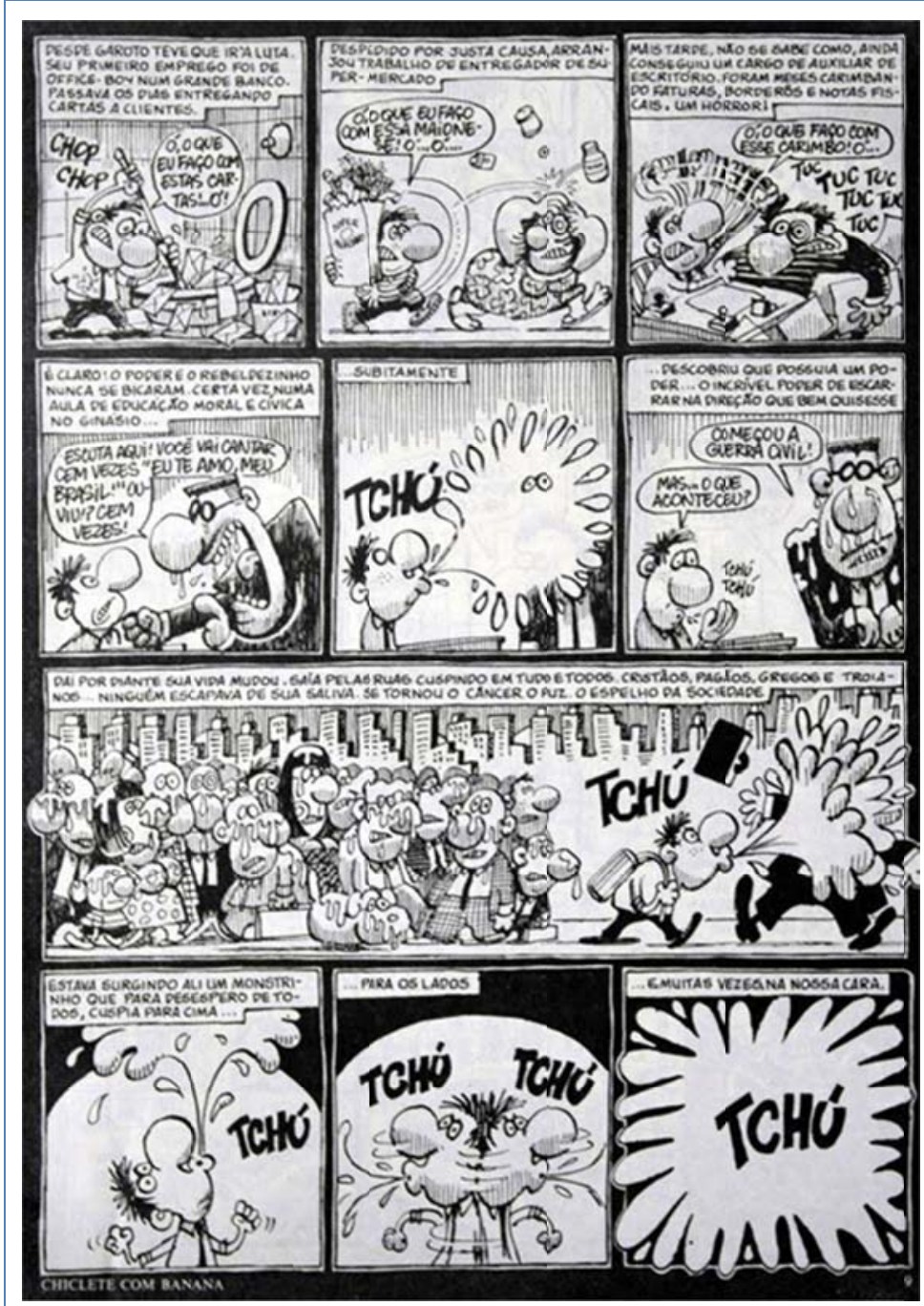

FIG. 04: Chiclete com Banana n.1. - Out/1985, p. 8. Acervo Pessoal.
A cuspida inaugural de Bob Cuspe ocorreu de forma súbita, ainda no ginásio, como resposta à punição imposta pelo seu professor de Moral e Cívica, "cantar cem vezes 'eu te amo meu Brasil"'. O gesto, banal, torna-se uma forma de ação e expressão difusas que contrariam um conjunto de valores em questão. Esse aspecto de reação fica claro pelo momento eleito pelo autor para que se efetivasse a grande transformação do personagem: a aula de Moral e Cívica.

Ou sejal, diante da estratégia empregada pela ditadura militar para formar crianças, jovens e adolescentes

em conformidade com valores patrióticos e cívicos estabelecidos pelo governo como ideais (ROLLEMBERG, 2006).

Tratou-se, portanto, de um ataque que tinha um alvo específico, o professor de Moral e Cívica, ou talvez possamos falar o poder disciplinar, afinal a legenda no quadrinho afirma “(...) o poder e o rebeldezinho nunca se bicaram"; mas podemos inferir que ele se estende também para hierarquias sociais, instituições, responsáveis, dirigentes e tudo que garante o funcionamento do poder. Ao desejo de condução expresso pelo seu 
Classifico, assim, as ações de Bob Cuspe como pequenos pontos de instabilidade que se não destituem os dispositivos de controle social e político, contribuem para a sua desestabilização. Ao chamar a atenção para a vitalidade dessas formas microscópicas de resistência, estou também apontando para a sua força, e é nesse sentido que o conceito de "potência de não" elaborado com acuidade por Agamben, no artigo "Potência de Pensamento" (2015b) mostra-se pertinente.

Agamben fundamenta suas ideias a partir da digressão que faz da doutrina aristotélica acerca das faculdades da potência e da "presença privativa da potência" dos sujeitos.

Toda potência de ser ou fazer algo é, de fato, (...) sempre também potência de não ser ou de não fazer, uma vez que, de outro modo, a potência passaria desde sempre ao ato e com este se confundiria (...). Essa "potência de não" é o segredo cardeal da doutrina aristotélica sobre a potência, que faz de toda potência, por si mesma, uma impotência. (...) (AGAMBEN, 2015b, p. 14)

Esse conceito é aprimorado quando Agamben se dedica a analisar a história do escrivão Bartleby, personagem de Melville (2008), apresentado como o "escriba que cessou de escrever (...) figura extrema do nada do qual procede toda a criação e, ao mesmo tempo, a mais implacável reivindicação desse nada como pura, absoluta potência. "(AGAMBEN, 2015a, p. 26).

Bartleby é um personagem que personifica um paradoxo, pois, ao mesmo tempo, simboliza o niilismo e encarna a potência absoluta de e de não. Com sua fórmula “prefiriria não", Bartleby exercita o seu poder de não escrever, ou seja, coloca em ação a privação. Ao direcionar essa reflexão para Bob Cuspe, proponho pensá-lo como uma tradução contemporânea da fórmula de Bartleby: prefiro não.

Com isso, pretendo redimensionar sua inoperatividade, dando-lhe um novo sentido: o de contracondutas que não almejam eliminar os dispositivos de controle e as redes de poder existentes, uma vez que as percebem como partes indissociáveis da sociedade em que vive, mas ainda assim as recusam reiteradamente, através de seus 
gestos, bem como as desqualificam e as pervertem, tornando-se assim oscilações permanentes no seu interior.

A partir do momento em que o personagem "descobriu que possuía um poder... o incrível poder de escarrar na direção que bem quisesse", toma o controle de si e passa a conduzir a si próprio. Conforme consta na legenda da história em questão, tem início a partir de então "a guerra civil".

Após a descoberta do novo potencial, $\mathrm{o}$ personagem resolve assumir um visual que o torne distinto da estética do belo, tornando-se assim grotesco (BAKHTIN, 1993). Ao mesmo tempo em que se distingue da estética padrão - perfeita e preestabelecida -, sua aparência torna-se tão "espetada quanto os tempos de hoje", ou seja, ele expressa o tempo em que vive: a metade da década de 80 , em que o Brasil ainda se encontrava mergulhado em incertezas políticas e em graves fraturas ideológicas.

Ao lado do caráter escatológico de seus gestos, a imagem agressiva e grotesca de Bob Cuspe torna-se uma forma de

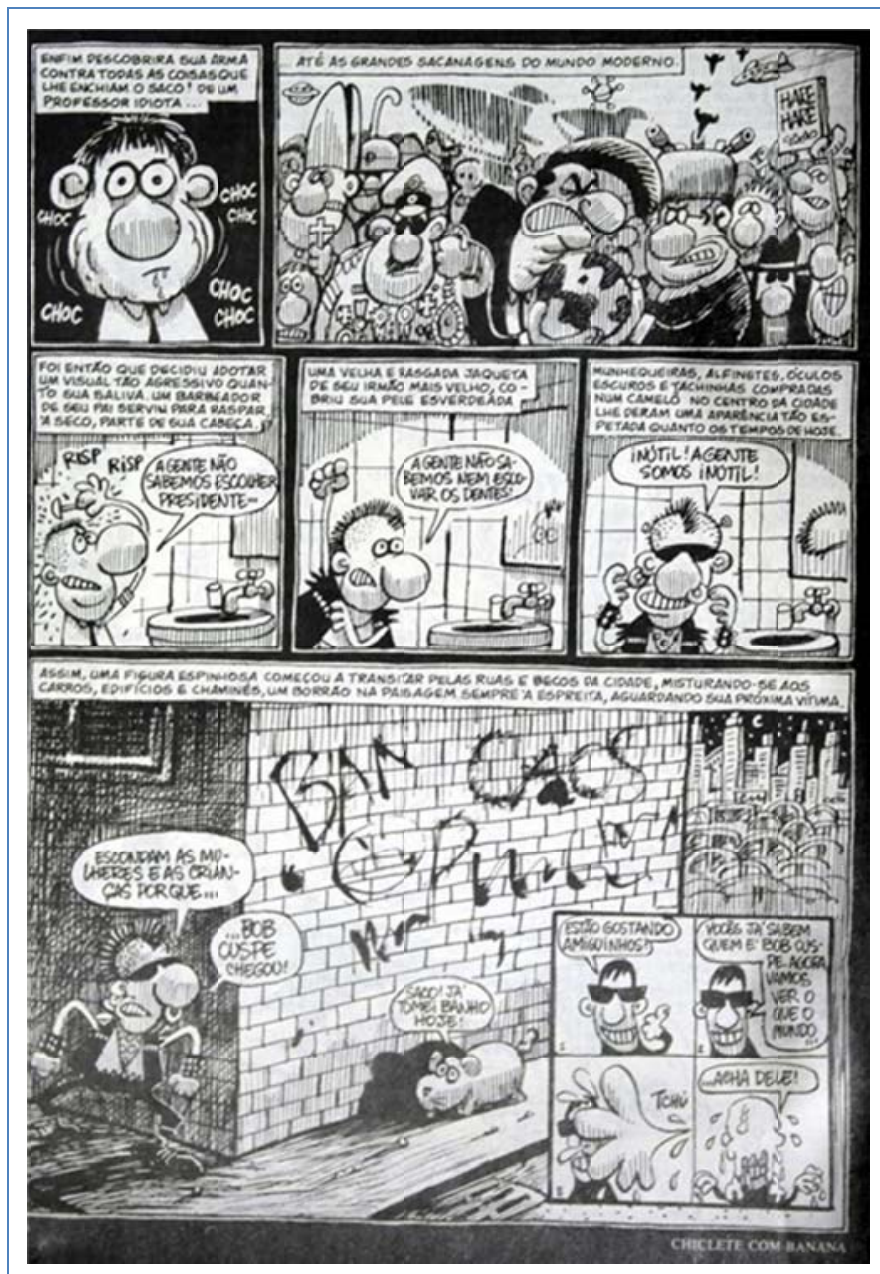

FIG. 05: Chiclete com Banana n. 1. - Out/1985, p. 8. Acervo Pessoal. rebaixar e degradar tudo aquilo que se apresenta como superior ou estabelecido. Juntos - aparência e gesto - atuam como práticas de negação de toda uma estrutura de vida, e não só de elementos particulares dessa estrutura.

Por isso, como consta na legenda da história, se dirigem "a todas as coisas que lhe enchiam o saco! De um professor idiota... até as grandes sacanagens do mundo moderno". Ao incidir em pontos tangíveis e particularizados da estrutura social, o caráter 
Outro aspecto interessante, nesse momento inaugural, é que embora ele represente uma investida contra o poder, não há nenhum gesto ou manifestação discursiva que revele a intenção de tomada do poder. Entretanto, esse não desejo de mudança radical não o torna inerte ou pacífico. Mais do que refletir sobre os modelos políticos e econômicos vigentes e indicar suas contradições, ser crítico do sistema, nesse contexto, implica em perceber-se imerso nessas contradições e abordar as plurais e complexas redes de poder existentes nas suas distintas formas de manifestação.

O autor emprega o distanciamento como uma estratégia discursiva para tornar estranho aquilo que, em geral, é visto como familiar, numa espécie de desvelamento que serviria para apresentar ao leitor uma perspectiva sobre as questões vivenciadas naquele momento sem, no entanto, sugerir uma alternativa ou respostas às mesmas.

Nesse sentido, o enfrentamento que ocorre entre o personagem e o professor que figura como representante do poder, parece ter a intenção de freá-lo, desmobilizá-lo, “obrigá-lo a recuar e a rearticular-se, ou, até mesmo, construir novos espaços de luta” (ALVIM, 2011, p. 42). O que se coloca em disputa é algo muito caro ao poder disciplinar: a conduta. Esta é, ao mesmo tempo, alvo e objeto tanto do seu representante, como do personagem.

\section{AQUEBRADA DA ESQUINA}

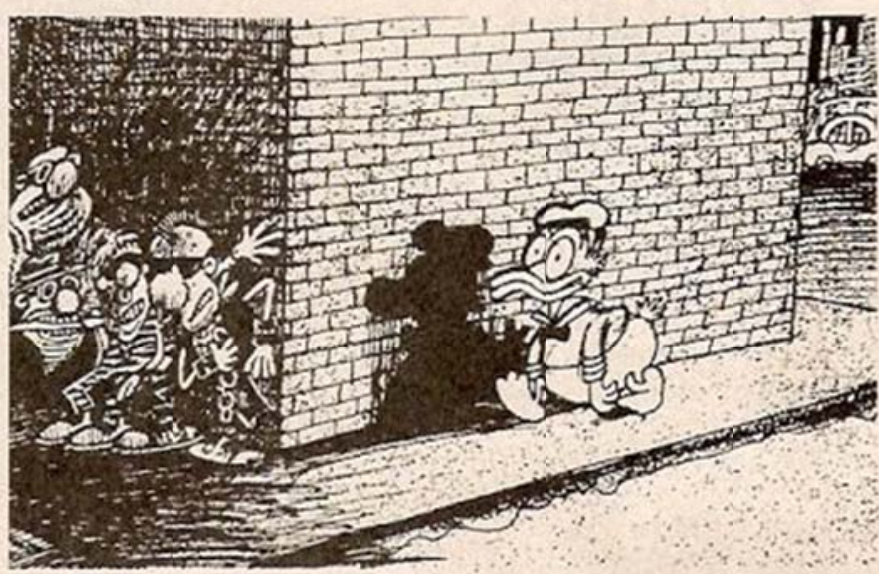

FIG. 06: Chiclete com Banana n.1. - Out/1985, p. 8. Acervo Pessoal.
Uma segunda contraconduta que o personagem adota é a organização de uma contrassociedade nos espaços em que transita: becos, esquinas, esgotos e ruas da cidade. Quando me refiro à contrassociedade, estou pensando nas pequenas comunidades de marginais dos espaços urbanos que aparecem em suas histórias. 
Por viver nesses ambientes, Bob Cuspe é apresentado como estranho à sociedade - "câncer”, "pus", “um enorme furúnculo nas axilas da sociedade”, "um borrão na paisagem". Entretanto, o autor também o apresenta como o "espelho da sociedade", definição que o reinsere no habitat urbano na medida em que o identifica como reprodução da sociedade que o refuta e que também é refutada por ele. Ainda que o personagem prefira a reclusão nas partes "baixas" da cidade, ele está indissociavelmente atrelado às partes "altas", pois é dali que vem tudo que integra o seu submundo, de forma que ele se torna produto da cidade.

As relações que estabelecem entre si são sempre transitórias e privilegiam a inversão da hierarquia social, uma vez que a liderança, quando existe, é assumida pelo próprio Bob Cuspe, isto é, aquele com a vida mais desregrada e sem nenhum prestigio social. Assim, os modos de viver nos espaços urbanos eleitos por Angeli (não só nas histórias de Bob Cuspe), podem ser compreendidos como elogios à contingência e formas de dar a ver as dobras da cidade, aquilo que está cravejado em seu seio e que constitui o âmago de sua ambivalência.

A contrassociedade que Bob Cuspe articula é também formada por "comunidades de sentido", ou seja, a reunião de "indivíduos adeptos de um determinado estilo de vida, que compartilham determinados interesses e se identificam a partir deles - participantes, ou não, dos grupos undergrounds que surgem durante a década de 1980 e 1990" (LIMA, 2013, p. 81). O autor não só evoca um imaginário urbano (SILVA, 2001) a partir de sua própria experiência, como o reelabora no intuito de criar elos de identificação com o leitor.

\section{Conclusão}

Bob Cuspe se funda na tradição do grotesco e do absurdo. Através dos elementos que caracterizam o grotesco - misturas, superposições, celebração do feio, afronta aos cânones da beleza - ele aborda o tempo em que vive, as linguagens faladas, os códigos compartilhados, as contradições próprias do sujeito urbano para o qual se dirige. Fala daquela sociedade fragmentada, dividida, fora de eixo. De alguma forma, pode-se afirmar 
Ao examinar esse personagem, visualizamos o público para o qual tais publicações se direcionavam: jovens viventes nos conturbados e instáveis anos 80 , após duas décadas de ditadura, que optaram - ou foram levados a optar - por uma postura oposta ao engajamento que caracterizara a juventude dos anos 60, assumindo uma conduta pessimista e crítica da política e do sistema capitalista sem, contudo, apresentarem uma resistência ao sistema, já que não buscavam a instauração de um novo modelo político, econômico ou social, mas especificamente sua problematização.

Com personagens como Bob Cuspe, Angeli não se mostra alheio às questões daquele momento histórico. Ao contrário, creio que se mostra absolutamente atento às novas demandas políticas e culturais do período e, em várias histórias que, por questões práticas, optei por não expor nesse artigo, soube mostrar a continuidade do arcaico em paralelo às condições de ruptura inauguradas. Penso nesse personagem como um recurso empregado pelo intelectual humorista para abordar de forma densa e complexa a precariedade característica do sujeito contemporâneo, vivente nas condições de instabilidade próprias daquele contexto histórico sem, com isso, ter a pretensão de tornar-se um "tradutor da verdade".

Nesse sentido, entendo que Bob Cuspe pode ser concebido como uma forma de crítica aos sistemas de ordenamento políticos e sociais estabelecidos, que se expressa através das contracondutas, ao mesmo tempo em que prenuncia uma crise da governamentalidade (SENELLART, 2008).

Momentos de crise e transição são também momentos de incertezas terminológicas, fazendo-se necessário, muitas vezes, a criação de novos termos e práticas para darem sentido ao que se vive, e tais escolhas nunca podem ser consideradas neutras, elas implicam numa tomada de posição quanto à natureza do fenômeno que se quer abordar e quanto à lógica mais adequada à sua compreensão.

Então, quando voltamos nosso olhar para personagens como Bob Cuspe, produzidos em momentos de crise, não podemos desconsiderar as categorias 
O grande feito do personagem está exatamente na recusa e na sua condição de exclusão, pois só através dela é possível "agrupar os insatisfeitos do mundo" e transitar livremente "entre bueiros, encanamentos e esgotos das cidades (...) encarar o ser humano por diversos ângulos (...) e saber o peso e o odor da civilização moderna" (ANGELI, 1985, p. 05).

Foucault assinala que o poder está e emana de toda parte e que pontos de resistência são indissociáveis do poder, pois dele são o "interlocutor irredutível" (FOUCAULT, 1988). Aliás, um aspecto interessante pontuado pelo autor é que não se pode falar em resistência no singular. Elas só existem no plural, são "possíveis, necessárias, improváveis, espontâneas, selvagens, solitárias, planejadas, arrastadas, violentas, irreconciliáveis, prontas ao compromisso, interessadas ou fadadas ao sacrifício (...)" (FOUCAULT, 1988, p. 91).

O personagem Bob Cuspe pode ser uma forma de pensarmos sobre as novas práticas de resistência que ganham espaço no Brasil dos anos 80 . Contracondutas que se apresentam "tão inventiva, tão móvel” quanto o poder, e que, como ele, "vem de baixo e se distribui estrategicamente" (FOUCAULT, 2004, p. 241). Assim, o que um personagem dessa natureza pode propor é a visibilidade de uma outra conduta que tenta se desprender das condutas impostas pelos outros, se autoconduzindo.

A especificidade de sua ação está em assumir a contraconduta como conduta, afinal "assim como houve outras formas de resistência, igualmente desejadas, ou de recusa que se dirigem ao poder na medida em que ele explora economicamente, não terá havido formas de resistência ao poder como conduta?" (FOUCAULT, 2008, p. 257).

É sobre as novas formas de sublevações, que, em geral, são colocadas do lado de fora da história, que nos movimentamos com essas reflexões, no intuito de reintroduzilas na história, junto com outros objetos que possam nos fazer pensar sobre elas e sua validade política em nosso tempo contemporâneo. 


\section{Referências}

AGAMBEN, Giorgio. Bartleby ou da contingência. Belo Horizonte: Autêntica Editora, $2015 a$.

AGAMBEN, Giorgio. A Potência do pensamento: ensaios e conferências. Belo Horizonte: Autêntica, 2015b.

AGAMBEN, Giorgio. O Que é o contemporâneo? e outros ensaios. Chapecó, Santa Catarina: Argos, 2009.

ANGELI. Chiclete com Banana. São Paulo: Circo Editorial Ltda, n. 01, Out, 1985.

ALVIM, Davis M. Foucault e Deleuze: deserções, micropolíticas, resistências. 2011. Tese (Doutorado em Filosofia ) - Pontifícia Universidade Católica de São Paulo, São Paulo: Programa de Pós-Graduação em Filosofia, 2011.

BAKHTIN, Mikhail. A cultura popular na idade média e no renascimento: o contexto de François Rabelais. São Paulo: Hucitec; Brasilia: Editora da Universidade de Brasilia, 1993.

BAUDRILLARD, Jean. À sombra das maiorias silenciosas: o fim do social e o surgimento das massas. São Paulo: Brasiliense, 2004, p. 56.

DANTAS, Daiane F. Não sei se caso ou se compro uma vodka: a mulher no quadrinho underground brasileiro dos anos 80. In: Anais VII Asociación Latinoamericana de Investigadores de La Comunicación - ALAIC. La Plata, ALAIC, 2004.

DELEUZE, Giles. Conversações. São Paulo: Ed. 34, 2010.

DINIZ, Paulo Fernandes Dias. Os quadrinhos de Angeli e o contemporâneo brasileiro. 2001. Dissertação (Mestrado em Comunicação Social) - Universidade Federal de Pernambuco. Recife: Programa de Pós-graduação em Comunicação, 2001.

FOUCAULT, Michel. História da sexualidade I: a vontade de saber. Rio de Janeiro: Edições Graal, 1988.

FOUCAULT, Michel. Microfísica do poder. Rio de Janeiro: Edições Graal, 2004.

FOUCAULT, Michel. Segurança, território e população. São Paulo: Martins Fontes, 2008.

FUKUYAMA, Francis. O fim da história e o ultimo homem. Rio de Janeiro: Rocco, 1992. 
GABROIS, Pedro Fornaciari. Resistência e revolução no pensamento de Michel Foucault: contracondutas, sublevações e lutas. Cadernos de Ética e Filosofia Política. São Paulo: USP, v. 19, n. 2, p. 07-27, 2011.

HUNTINGTON, Samuel Phillips. O Choque das civilizações e a recomposição da nova ordem mundial. Rio de Janeiro: Objetiva, 1997.

JAMESON, Frederic. Pós-Modernidade e sociedade de consumo. Novos Estudos CEBRAP. São Paulo, n. 12, jun., 1985.

LIMA, Jefferson. Bob cuspe: a representação de Angeli do Punk Paulistano na Revista Chiclete com Banana (1985-1991). 2013. Dissertação (Mestrado em História) Universidade do Estado de Santa Catarina, Centro de Ciências Humanas e da Educação, Mestrado em História, Florianópolis, 2013.

MELVILLE, Herman. O Escrivão ou Bartleby, o escriturário. São Paulo: L\&PM, 2008.

NOVAES, Adauto. A lógica atormentada. In Novaes, A. (Org). A crise da razão. São Paulo: Companhia das Letras, 1996.

PLAYBOY, São Paulo: Editora Abril, ano 32, n. 375, p. 68, set., 2006.

ROLLEMBERG, Denise. A ditadura civil-militar em tempo de radicalizações e barbárie. 1968-1974. In MARTINHO, F. C. P. (Org.). Democracia e ditadura no Brasil. Rio de Janeiro: EdUERJ, 2006, p. 141-152

SANTOS, Aline Martins dos. "Udigrudi": o underground tupininquim. Chiclete com Banana e o humor em tempos de redemocratização brasileira. Dissertação (Mestrado em História) - Universidade Federal Fluminense. Rio de Janeiro: Programa de Pós-Graduação em História, 2012.

SENELLART, Michel. Situação dos Cursos. In FOUCAULT, M. Segurança, território e população. São Paulo: Martins Fontes, 2008. p.495-538.

SILVA, Armando. Imaginários urbanos. São Paulo: Perspectiva, 2001.

SILVA, Benedicto. (Coord). Dicionário de ciências sociais. Rio de Janeiro: FGV, 1986

SILVA, Keliene Cristina da. Angeli e a República das Bananas: representações cômicas da política brasileira na revista Chiclete com Banana (1985-1990). 2011. Dissertação (Mestrado em História) - Universidade Federal da Paraíba, Programa de Pós-Graduação em História: João Pessoa, 2011. 
SILVA, N. M. Fantasias e cotidiano nas histórias em quadrinhos. São Paulo: Annablume, 2002.

VERGUEIRO, W. Chiclete com Banana de Angeli. In MENDES, T. (Org.). Humor Paulistano: a experiência da Circo Editorial (194-1995). São Paulo: SESI-SP editora, 2014. 